\title{
Professional public accreditation of educational programs in the education quality assessment system
}

\author{
Vladimir Demidov ${ }^{1}$, Dmitriy Mokhorov ${ }^{1}$, Anna Mokhorova ${ }^{1, *}$, and Kristina Semenova ${ }^{1}$ \\ ${ }^{1}$ Peter the Great St. Petersburg Polytechnic University, Humanitarian Institute, Politekhnicheskaya \\ Ulitsa, 29, St Petersburg, 195251, Russia
}

\begin{abstract}
This article aims to examine professional public accreditation of educational programs as a means of ensuring that higher education remains relevant to the current socio-economic public needs in the context of shifting requirements of the labour market, digitalization of most areas of life, and new challenges in technical and technological development. The study actualizes new approaches that can be used in assessing the quality of educational programs implemented in the field of environmental management, energy, and environmental protection. A systems approach views professional public accreditation of educational programs as a set of measures. They aim to ensure the compliance of educational programs with the requirements of professional standards and employers' expectations. An institutional approach enabled to identify the subjective characteristics of the examined phenomenon. We also used methods of problem analysis, comparative analysis, data collection, and statistical processing. The result of the study is the established need to develop professional public accreditation of educational programs in the system of independent assessment of education quality, which would make it possible to estimate the significant characteristics of an educational program and to determine whether its implementation in a specific timespan is necessary. This study can contribute to the development of the specific practices of professional public accreditation of educational programs, including in the field of rational and sustainable use of natural resources, and it can facilitate the development of the legal, theoretical, and organizational foundations of this type of public activity.
\end{abstract}

\section{Introduction}

The policies of many countries aim to develop a high-quality education system. It is possible only by creating a complex of independent quality assessment based on state standards and requirements as well as on public organizations and independent experts. The latter build their professional activity upon keeping the interests of employers and the academic community [1]. Accreditation has become an important direction in the assessment of the quality of educational services in most countries. In the United States and

* Corresponding author: mokhorova@list.ru 
European countries, the system of public accreditation of educational programs or educational institutions began to take shape in the second half of the 20th century [2], while Russia has just stepped on the path of developing this line of activity [3].

Although legal prerequisites for the implementation of professional public accreditation of educational programs were laid down in Russian regulations as far back as the 1990s (for example, according to the legislation that was in force at the time, educational institutions could be publicly accredited by various authorities, both Russian and international, if such accreditation did not incur extra costs for the state, while state authorities were responsible for assisting in public accreditation (Article 37 of the 1992 Law on Education); Article 4 of the Law on Higher and Postgraduate Professional Education (Federal Law of August 22, 1996, No. 125-FZ) established that "the structure of higher and postgraduate professional education is a combination of: ... public and state-public associations (creative unions, professional associations, societies, scientific and methodological councils, and other associations)" and contained other provisions which implied that public accreditation could serve as a means of assessing the quality of higher education). This concept did not gain traction in education quality assessment. There are many possible reasons for this, ranging from the lack of interest from higher education institutions [4] to the lack of support and recognition from public authorities [5]. Nevertheless, the groundwork for the formation and development of this progressive institution was laid by Federal Law of December 29, 2012, No. 273-FZ on education in the Russian Federation.

This regulatory act established the rights of employers and their associations in the field of education, including the right to participate in public accreditation or professional public accreditation, which, in turn, could be used in the state accreditation of educational organizations. However, the professional community and educational institutions have not developed regulations yet, which raises reasonable doubts about the objectivity and effectiveness of this tool in education quality assessment. Therefore, the role of the examined instrument in education quality control generates a wide discussion in scientific literature and academic circles.

On the one side, it is possible to resolve the known problem of contradictions between the knowledge of graduates and the requirements of employers through the use of the phenomenon under study [6], and on the other side, there are numerous unresolved issues related to the differentiation of this type of education quality assessment from other procedures, as well as to setting the criteria for professional assessment of education [7], determining the indicators and methods to assess the extent of employer's participation in the assessment of educational programs [8].

\section{Literature review}

At present, accreditation issues receive increasing attention due to the need to improve the quality of education in general and higher education in particular [9-12]. Both international and Russian experience in conducting public accreditation is of interest for developing criteria and mechanisms for its implementation.

Thus, considering the issues of public accreditation in the U.S., which have accumulated a huge experience in conducting such a procedure, the authors note the peculiarities of the structure of the education system, which may differ significantly from state to state, and the "spontaneous" way of forming the "accreditation system (organizationally and procedurally) - as a result of the initiative of professional associations, public associations, and educational organizations themselves" [13, p. 20]. Thus, national and regional nongovernmental organizations funded by university contributions conduct external assessment of the quality of education in the United States. [14-15]. It is important for objective assessment and re-accreditation deadlines. As the review teams that visit the institutions as 
part of the accreditation and reaffirmation process involve volunteers from institutions also accredited by that agency [16-18]. Thus, in the U.S. more attention is paid to the quality of the procedures and the objectivity of their conduct.

European authors focus on the analysis of the system of regulations governing the system of professional public accreditation, the legality and legitimacy of public accreditation procedures concerning educational reforms in general [19-21].

Researchers define the powers of accreditation bodies, to establish significant requirements for educational programs within the framework of accreditation and to study its procedure [22]. In addition, scientists pay attention to the influence of public accreditation on the quality of higher education programs. Thus, analysis of public accreditation of educational programs in Portugal indicates that this accreditation has had a powerful impact, reducing the number of programs, increasing the number of $\mathrm{PhD}$ holders among teaching staff and raising institutional awareness of quality [23].

Most authors agree that in developing countries the influence of accreditation contributes significantly to enhancing the University quality of teaching, learning, research and management [24-28].

Researchers pay a great deal of attention to the issue of globalization in higher education, which affects many countries around the world; they describe international accreditation procedures and their impact on educational processes in developing countries. For example, researchers explore the role of international accreditation in quality assurance of educational services in the countries of the Bologna Process. They establish that it influences the adaptation of international quality standards in the national system of education quality control. [29-30]. Or the activity of American accreditors in the Middle East countries that carry out international accreditation of certain educational programs on the basis of common standards and requirements defined by accreditation agencies of the US [31-32]. This determines the need to take into consideration national peculiarities when "exporting" accreditation technologies.

Russian literature pays considerable attention to the issues of education quality assessment conducted by independent non-governmental experts [33-34]. Studies aim to examine the procedural problems of professional public accreditation and determining the criteria for assessing the quality of educational programs and methods of conducting the procedure itself [35- 40]. In the article "Piloting a new set of the AEER accreditation criteria" [41], the authors describe the experience of applying new criteria for the accreditation of educational programs in higher and secondary vocational education in technology. This would improve the training of engineers for production and ensure international recognition of graduates.

Several works are devoted to the development of accreditation criteria for humanitarian programs [42] and the improvement of their quality [43-44]. Of particular interest among the above works are studies aimed at analyzing problems identified in the process of professional public accreditation and suggestions for improving this procedure [45]. In particular, there is the problem of subjective understanding of assessment criteria by various experts [46-47]. As a solution to this problem, researchers rightfully suggest conducting a preliminary discussion of the established assessment criteria to achieve a unified and uniform understanding of them. Furthermore, the study devoted to increasing the efficiency of professional public accreditation proposes improving the system for assessing the quality of professional educational programs.

There are also studies on the significant development patterns of professional public accreditation in Russia, which indicate a significant increase in the number of accreditation agencies and higher education institutions participating in accreditation. The study also describes the role of the government in the development of professional public accreditation and assesses its effectiveness [48-50]. 
Also of interest is another study aimed at examining the specific features of professional public assessment of additional vocational education programs. The authors address the issue of the ways to assess educational programs that are not subject to the requirements of federal state educational standards. The authors consider additional vocational education programs as one of the ways to duly update education in the context of dynamic, rapidly changing knowledge and technology. Taking into account these features of additional vocational education programs, the authors of the study highlight the specific aspects of professional public accreditation concerning this type of education. The authors of the article believe that assessment of the quality of additional vocational education programs should be conducted not by the state or professional communities, but by particular independent associations controlling the quality of educational services, which already exist in Europe [51; 52].

Thus, the authors cover public accreditation of educational programs in modern literature from various perspectives. The main provisions, studied in the works, are: definition of the criteria of the procedure under consideration and their incorporation into the legislation, which will allow avoiding subjectivism in the process of accreditation and improving its effectiveness; determination of the dependence of the quality of education on the conducted accreditation procedures; study of public influence on educational processes, as well as the use of international experience and standards in conducting public accreditation procedures.

\section{Methodology}

Following the aim of the study - to examine professional public accreditation (from now on PPA) of educational programs as a means of ensuring that higher education remains relevant to the current socio-economic public needs - the following research methods were used.

Within the framework of the institutional approach, PPA was regarded as a particular legal institution in the system of Russian Law, which has particular specifics and cooperates with other institutions that regulate the implementation of educational quality assessment.

According to Article 96 (4) of the Federal Law of December 29, 2012, No. 273-FZ on education in the Russian Federation, "professional public accreditation of professional educational programs involves recognizing that the quality of education and the competence of the graduates of an educational program of a specific organization implementing educational activities meet the requirements of professional standards and requirements of the labour market to the professionals, workers, and employees of the corresponding specialization".

Within the framework of the systems approach, we determined that PPA of educational programs is a system comprising a significant number of interdependent elements and itself being an element of the education quality assessment system interconnected with other types of accreditation. Thus, we analyzed the significant aspects of state accreditation and public accreditation to determine their similarities, differences, and points of contact in the system of education quality assessment.

The analysis allowed us to identify the essential aspects of the system of PPA of educational programs: subjects, objects, purpose, content, and result. The subjects of PPA of educational programs include educational institutions on the one side, and accreditors on the other side. Considering that the subject of this study is PPA of higher education programs, the mandatory issue is an educational organization implementing bachelor's (academic), specialist's, and master's programs. An accrediting or other organization included in the list of organizations conducting PPA of higher education programs can act 
as an accreditor. By the Decree of the Government of the Russian Federation of November 29, 2018 No. 1439 on amendments to several acts of the Government of the Russian Federation, the Ministry of Science and Higher Education of the Russian Federation is responsible for compiling and maintaining a list of such organizations as well as for making it publicly available on the Internet via the official website of the Ministry of Science and Higher Education of the Russian Federation.

The official website of the Automated Information System for the Monitoring of Professional Public Accreditation of Educational Programs https://accredpoa.ru/ has a list of 102 accreditors.

Secondary professional education and higher education programs and the related supplementary vocational education programs are the object of PPA.

The primary purpose of professional public accreditation is to conduct an independent objective assessment of the quality of education under the accredited educational program based on indicators ignored during state accreditation and based on the analysis of demand for graduates in the labour market, compliance of their skills with the requirements of employers, and best practices and significant achievements of the educational institution.

Professional public accreditation of educational programs is voluntary. It begins upon application by an organization implementing educational activities to a public organization implementing professional public accreditation.

Organizations conducting professional public accreditation of educational programs are at liberty to determine the procedure, including the choice of forms and methods for assessing educational programs.

Due to the lack of clear regulations, accreditation can be conducted either on-site or offsite, based on information provided by the accredited educational organization and publicly available on the Internet and in other mass media.

\section{Results}

PPA of educational programs is one of the new directions for assessing the quality of education in the Russian Federation. The above-referenced Federal Law provides its legal framework; it establishes the possibility of conducting the following types of accreditation: state accreditation, public accreditation of organizations implementing educational activities, and professional public accreditation of educational programs.

The Law also defines education system management, which includes, among other things, independent assessment of the quality of education and public professional accreditation. That said, professional public accreditation of educational programs and public accreditation of organizations have independent importance and are not included in the system of standards for an independent assessment of the quality of education.

Subordinate laws and regulations of the government and federal executive authorities do not provide legal content for PPA.

Consequently, it leads to a crucial problem to differentiate different types of accreditation available in the Russian Federation. Relying on the current legislation, the authors of this article undertake comparison of the different types of accreditation.

Based on the obtained data, we can conclude that state accreditation is sufficiently regulated both at the legislative level and at the level of laws and regulations of federal executive authorities. As for other procedures, only their general framework is outlined in legislation, and they are mainly regulated by the acts of organizations that conduct these types of accreditation. Such broad dispositiveness in determining the procedures that affect education quality assessment is an adverse factor for the development of these types of accreditation, preventing their active implementation in education quality assessment. 
When conducting accreditation, accreditors rely upon the Basic Principles of Professional Public Accreditation of Professional Education Programs developed by the Presidential National Council for Professional Qualifications on April 20, 2015.

According to the Basic Principles, the primary criteria for the successful completion of professional public accreditation include:

- compliance of the professional qualifications of graduates with the requirements for an independent assessment of professional qualifications;

- compliance of the planned learning outcomes of the assessed program with professional standards;

- compliance of the curriculum, work programs, etc. with the planned learning outcomes of the assessed educational program;

- adequate level of material, technical, educational, methodological, and other resources that affect the quality of educational services;

- demand for the professional education program and the employment rate of graduates under the assessed educational program;

- the practical orientation of the topics of graduation theses, practical training programs, the participation of the employer in the formation of the significant documents under the assessed educational program.

In addition to the above, accreditors can introduce additional criteria developed within their organization. For example, the National Association for Territorial Self-Government sets additional standards for the teaching staff, students, and research programs of an educational organization when assessing educational programs in the field of Law - in addition to the general requirements outlined in the Basic Principles of Professional Public Accreditation. As part of its methodology, this accreditor also conducts an additional assessment of the level of interaction of the educational organization with professional and business communities; the efficiency and rationality of the educational organization's management system and the level of its cooperation with other educational organizations, including international ones [53].

The Expert Center of the Association of Lawyers of Russia sets similar criteria. However, they have additional requirements for "library and information resources" [54]. The Kaliningrad Chamber of Commerce and Industry, apart from the essential criteria, establishes an additional requirement for the quality management of the educational program [55].

The Association of Classical Universities of Russia also assesses the "socio-cultural environment", which should create appropriate conditions for the comprehensive personal development of students, including their professional, creative, and physical abilities. This accreditor requires the socio-cultural environment of the educational institution to be equipped with the permanent museum and library resources, and it determines whether university has a well-developed system for ensuring the quality of services provided and the reliability, completeness, relevance, and availability of information supplied by university about the assessed educational program and educational institution [56].

It is also important to note that professional public accreditation is a voluntary procedure conducted at the expense of the educational organization and does not provide any rights or benefits from the state. However, its results can be:

- considered during state accreditation (Article 96(8) of the Federal Law on Education in the Russian Federation);

- used by employers and their associations when ranking educational programs accredited by them and organizations implementing educational activities (Article 96(5) of the Federal Law on Education in the Russian Federation);

- considered in the process of allocating admission quotas funded through budgetary appropriations (Order of the Ministry of Education and Science of the Russian 
Federation of July 15, 2013 No. 560 on approval of the procedure of allocating admission quotas for citizens by profession, speciality, and field of study under stateaccredited secondary vocational and higher education programs funded through budgetary appropriations of the federal budget);

- used in inter-university and international cooperation and to strengthen the image of the organization implementing educational activities.

\section{Discussion}

According to Fitch K. [6] «as early as the 1950s, there was an ambiguous attitude to the significance of higher education as preparation for a career». Later this attitude gradually faded away. PPA of educational programs implies the assessments of the major consumers of educational services, primarily employers, for whom the result of educational activities is essential, not the process itself. However, the result is usually outside the scope of assessment of state accreditation. The opinions and demands of parents and students are also crucial for the public assessment of the quality of education. Thus, PPA of educational programs is to combine expectations of employers and capacities of education institutions when developing competencies of graduates [57]. This means that criteria developed for PPA will not coincide with the provisions applied to state accreditation.

The accreditation of educational programs is voluntary and self-regulating [58; 59], which leads to a crucial problem of public notice of the accreditation results.

The question of whether it is appropriate to publish information about educational organizations that participated in professional public accreditation but did not pass it due to non-compliance with the established criteria is quite complex. On the one hand, disclosure of such information is necessary to protect the interests of applicants, students, and employers. However, considering the ability of accreditors to set their criteria for the successful completion of professional public accreditation and the subjectivity of expert assessment, distribution of information about the failure to pass PPA may create additional risks for the reputation of higher education institutions.

Furthermore, taking into account the fact that successful completion of professional public accreditation can give universities additional opportunities in the allocation of admission quotas, and thus affect the distribution of budget appropriations, the state should carefully control the procedure of assessing educational programs. Therefore, some authors highlight the necessity to integrate the state and public accreditation $[60 ; 61]$.

Thus, the priority task of PPA of educational programs is to create conditions for an objective assessment of the competence of university graduates who have completed the program submitted for accreditation, harmonization of interests between labour and education [62]. This goal should also be closely related to the specific demand for graduates from higher education institutions by the economic entities that a particular educational institution focuses. The following points are particularly crucial for PPA of educational programs in the higher education system. First, achieving the necessary level of education in a specific professional field. Second, the practical implementation of professional accreditation open for all interested parties. Third, sufficiently high awareness of legal entities and the population about the quality of educational programs implemented by a particular university, creating conditions for a mutually acceptable level of cooperation between universities and institutes on the one side and organizations engaged in economic activities on the other side. Fourth, providing real assistance in creating a system that would guarantee a high level of education at a university. At the same time, it must meet national and global standards for higher education. Fifth, making it possible to determine the most top quality higher education programs in a competitive environment. Sixth, defining the 
prerequisites that would facilitate the orientation of higher education institutions towards the most advanced educational programs.

With these goals in mind, the following significant approaches are implemented in the PPA of educational programs. First of all, voluntary participation [58], i.e. a university or institute itself should determine whether it is appropriate to undergo this procedure and which educational programs are to be assessed. PPA of educational programs should be as open for interested parties as possible, and the final results of accreditation should be publicly available for employers, students, applicants, and their legal representatives. However, this openness is limited. According to the Law, proprietary information and trade secrets are strictly confidential, and educational programs pertaining to protected intellectual property.

One of the essential requirements is that there should be comparable procedures for an objective assessment of the quality of education and competence of students under a specific educational program regardless of university. Establishing uniform procedures would make it possible to build an objective hierarchy of the quality of educational programs [63].

Priority should be the quality assessment of programs by representatives of organizations devoid of departmental or university's affiliation to avoid the subjectivity of assessment and increase its credibility. In the assessment of educational programs, it is necessary to distinguish between the quality of an educational document and its impact on the competence of graduates in specific activities after graduation.

It is essential to use a systems approach to the assessment of all educational programs to achieve more reliable results. Another prerequisite is the competence of the persons conducting the assessment, methodological readiness for accreditation examination, information security, and unbiased approach.

The entire process of PPA of educational programs takes several months. It includes various steps: submission of a written application for this type of accreditation; inspection of documents defining the procedure; self-examination of university based on methods proposed by the accreditor; in-office assessment of educational programs by the accreditor. During PPA of an educational program, representatives of the expert community make field trips to take the necessary measurements, conduct interviews, and arrange meetings with interested parties. The next step involves preparing a conclusion of the expert commission based on the undertaken accreditation. Finally, the accreditor must decide according to local regulations. The accreditor has the right to issue a certificate confirming the compliance of educational programs with legal requirements.

The analysis of the current legislation enables highlighting several stages of the check [64]. At the preliminary stage, educational programs are examined extramurally to determine the extent of their compliance with the aspects of the project-based approach and to check whether they are oriented towards achieving high results in the learning process. At the first stage, direct representatives of economic entities and other parties sharing their interests assess the works of graduates under a specific educational program. At the second stage, representatives of legal entities and experts visit the higher educational institution to conduct an on-site examination of educational programs. They check whether the information provided in the self-assessment report correlates with professional standards and objective requirements of the economic environment. At the same time, experts develop the necessary recommendations for improving programs and the level of professionals produced by university. During the second stage, it is required to achieve close coordination between representatives of university and experts. The primary aspects of being assessed are the specific results of the implementation of educational programs and the sections of the self-assessment report that aroused the interest of experts. During their visit to the educational institution, representatives of the expert group meet with the 
managers of the educational institution and the persons responsible for developing specific educational programs. The experts thoroughly analyze the management of educational programs, discuss the use of advanced methods with the teaching staff, and carefully examine the curricula, educational programs, and teaching guidelines. During the second stage, experts should have access to all educational facilities and equipment, including computer classrooms. At this stage, it is stablished explicitly whether the content of educational programs corresponds to the actual educational process and how the content meets the interests of representatives of economic entities. It may be difficult for experts to provide a quantitative assessment of criteria due to primarily descriptive factors. Finally, experts often use different rating systems, and the difference between these rating scales does not fully reflect the views of experts conducting the assessment, which negatively affects the results of the study. It is possible to avoid the ambiguity of expert approaches by using a standardized procedure, because assessment criteria would not be related to the specific content of educational programs. This reduces the subjectivity of expert assessment, which has a positive impact on the results of the entire procedure. Expert opinions on the examination of educational programs can contribute to their improvement and structuring.

PPA conducted by authorized organizations results into, «first, removing risks for universities no to comply with international quality standards for higher education; second, it ensures the improvement of educational program structure; third, it contributes to development of the expert pool in higher education. The preparation for accreditation by international standards and rules, its information support, and a long-term experience of self-assessment, are a powerful incentive for development of all participants of the educational process» $[65]$.

Based on the results of accreditation, a higher education institution creates prerequisites for further improvement of techniques and methods that affect the development of educational programs [66]. Another critical effect of accreditation is the actual dissemination of advanced approaches in academic circles, allowing higher education institutions to meet the demand of legal entities for highly skilled professionals for commercial production in the context of market transformations. Considering that results of PPA of educational programs to analyze the effectiveness and efficiency of their practical implementation, this type of accreditation allows us to draw certain conclusions about the extent to which the developed educational programs meet the goals and objectives that higher education institutions pursue when training professionals necessary for the national economy at the present stage.

\section{Conclusion}

Having examined the institute of PPA of educational programs that is forming in the Russian legal system, we can draw the following important conclusions. Being one of the new types of accreditation provided for by Russian legislation, PPA of educational programs is actively developing, gaining a vital position in the system of education quality assessment and actively increasing the number of participants and the quality of examinations. Within the framework of PPA of educational programs, new assessment criteria being developed - such that would be important and necessary under current conditions with allowance for the interests of employers, the requirements of students, and the capabilities of educational institutions.

PPA of educational programs serves to assess the demand for the main direction of development of the educational program and its connection with real-life conditions in the labour market. It also aims to determine whether a professional with specific competencies would meet the demands of the market and the economy. We should note that documents 
regulating the implementation of educational programs should fully correspond to the competencies gained by university graduates. The level of satisfaction of representatives of business organizations and graduates of higher education institutions with the results of educational programs is an essential component. The teaching materials used by the teaching staff as well as the logistical conditions for the implementation of educational technologies directly influence the quality of educational programs. Another important aspect is the availability of financial and information resources, which affects the compliance of educational programs with the requirements established in the realities of economic activity.

On a positive note, we should note that as a result of this procedure, employers can form a competency model of a graduate following the needs of the market without implementing resource-intensive measures like training and retraining of personnel, and to order the training of specialists with the necessary qualifications.

For applicants and their legal representatives, PPA serves as a source of information, since it allows for a more reliable and objective assessment of the quality and demand for educational services provided by educational organizations. As a rule, the main goal of pursuing higher education is the professional fulfilment of the future graduate. In this connection, obtaining reliable information about the compliance of educational programs with the expectations of employers also performs an essential predictive function. This function allows applicants and their parents to evaluate the prospects for employment under the programs of specific universities to avoid spending time and money on non-demanded educational services.

For higher education institutions, participation in an independent assessment of the correspondence between the process and results of education allows them to more objectively assess and improve their competitiveness and reputation, determine the significant directions for the development of educational activities, and rationally allocate in-house resources.

A university or institute that has successfully passed PPA of educational programs has the right to present the results of the assessment of educational programs during state accreditation and, most importantly, during the distribution of admission quotas. Universities can also publish information about the completion of PPA of educational programs on their official website.

At the same time, considering the importance of the goals and objectives of independent assessment of the quality of educational services, its procedure should become as transparent and unified as possible, taking into account the specific aspects of the assessed field of study or specialty.

\section{References}

1. A. M. Aleksankov, V. E. Mager, L. V. Chernenkaya, A. V. Chernenkiy, Open Edu. 13(4), 10-16 (2016) http://dx.doi.org/10.21686/1818-4243-2016-4-10-16

2. W. B. Dunn, D. I. Broadhurst, A. Edison, C. Guillou, M. R. Viant, D. W. Bearden, R. D. Beger, Metabolomics, 13(5), 50 (2017) https://doi.org/10.1007/s11306-017-1188-9

3. V. S. Senashenko, E. P. Struchkova, Higher Edu. in Russia, 28(4), 9-20 (2019) https://doi.org/10.31992/0869-3617-2019-28-4-9-20

4. S. I. Nazarova, Management of edu.: theory and practice, 29, 53-61 (2018)

5. G. N. Motova, Higher education in Russia, 10(216), 13-25 (2017)

6. K. Fitch, In: Professionalizing public relations, 29-61 (Palgrave Macmillan, London, 2016) https://doi.org/10.1057/978-1-137-57309-4_2 
7. S. O. Shaposhnikov, E. Y. Yatkina, In: International conference "Quality management,transport and information security, information e" (IT\&QM\&IS), 443-446 (2019) (IEEE, 2017) https://doi.org/10.1109/ITMQIS.2017.8085857

8. M. Petropavlovskiy, O. Nefedova, V. Smelik, In: International scientific days. The agri-food value chain: challenges for natural resources management and society, 681687 (Slovak University of Agriculture in Nitra, 2016) http://dx.doi.org/10.15414/isd2016.s8.15

9. J. Kinzie, High Edu. Polic., 32, 577-595 (2019) https://doi.org/10.1057/s41307-01900148-y

10. G. Rhoades, B. Sporn, Higher Edu. 43, 355-390 (2002) https://doi.org/10.1023/A:1014659908601

11. C. S. Sarrico, A. A. Alves, Academic staff quality in higher education: an empirical analysis of Portuguese public administration education. Higher Edu. 71, 143-162 (2016) https://doi.org/10.1007/s10734-015-9893-7

12. M. L. Skolnik, Higher Edu. 71, 361-378 (2016) https://doi.org/10.1007/s10734-0159908-4

13. V. Zh. Kuklin, Accreditation in the Russian system of higher education: options for reform. Compliance assessment bodies. Internat. res. j. 12(90), 60-64 (2019) https://doi.org/10.23670/IRJ.2019.90.12.012

14. J. S. Eaton, Planning for higher education. 40(3), 8-15 (2012)

15. C. Kirkham, K. Short, Huffington Post http://www.huffingtonpost.com/2013/09/19/for-profitcollegeaccreditation_n_3937079.html

16. B. Brittingham, New Directions for Higher Education 145, 7-27 (2009)

17. J. S. Eaton, An overview of US accreditation. (CHEA, 2012)

18. A. L. Parkman, Exploring the relationship between accreditation and for-profit higher education institutions (The University of Arizona, 2018) https://repository.arizona.edu/handle/10150/628060

19. J. Baumann, G. Krücken, High Edu. Policy 32, 29-48 (2019) https://doi.org/10.1057/s41307-018-0120-X

20. M. J. Chisvert-Tarazona, In: F. Marhuenda-Fluixá (Ed.), The school-based vocational education and training system in Spain. Technical and vocational education and trainings: issues, concerns and prospects 32, 69-85 (Springer, Cham, 2019) https://doi.org/10.1007/978-981-13-8475-2_4

21. S. Peksen, N. Zeeman In: B. Broucker, K. De Wit, J. C. Verhoeven, L. Leisyte (Eds.) Higher education system reform : An international comparison after twenty years of Bologna, 37-52 (Brill Sense, 2019) https://doi.org/10.1163/9789004400115_003

22. C. Dowlen, In D. Schaefer, G. Coates, C. Eckert (eds), Design education Today, 293324 (Springer, Cham, 2019) https://doi.org/10.1007/978-3-030-17134-6_13

23. C. Sin, O. Tavares, A. Amaral, Assessment \& Evaluation in Higher Education, 42(6), 860-871 (2017) https://doi.org/10.1080/ 02602938.2016.1203860

24. J. Bongaarts, B. S. Mensch, A. K. Blanc, Population studies, 71(2), 139-154 (2017) https://doi.org/10.1080/00324728.2017.1291986

25. G. Blanco-Ramírez, J. B. Berger, Quality Assurance in Edu. 22(1), 88-104 (2017) https://doi.org/10.1108/QAE-07-2013-0031 
26. H. C. Nguyen, C. Evers, S. Marshall, Quality Assurance in Edu. 25(4), 475-488 (2017) https://doi.org/10.1108/QAE-11-2016-0075

27. H. C. Nguyen, T. T. Hien Ta, Tertiary Edu. and Manag. 24(2), 154-167 (2018) https://doi.org/10.1080/13583883.2017.1406001

28. M. J. Manatos, C. S. Sarrico, M. J. Rosa, Total quality manag. \& business excellence, 28(1-2), 159-175 (2017) https://doi.org/10.1080/14783363.2015.1050180

29. A. Margun, A. Kremlev, D. Bazylev, E. Zimenko, In V. Uskov, R. Howlett, L. Jain (Eds), Smart education and e-Learning SEEL 2017. Smart innovation, systems and technologies, Springer. 75, 450-458 (Springer, Cham, 2017) https://doi.org/10.1007/978-3-319-59451-4_45

30. M. Klassen, C. Sá, High Edu. 79, 159-174 (2020) https://doi.org/10.1007/s10734-01900403-6

31. B. Barrett, F. Fernandez, E. M. Gonzalez, High Edu. 79, 619-635 (2020) https://doi.org/10.1007/s10734-019-00427-y

32. M. Reeves, In Staub D. (ed), Quality assurance and accreditation in foreign language education, 37-54 (Springer, Cham, 2019) https://doi.org/10.1007/978-3-030-214210_4

33. R. P. Bulyga, A. N. Amerslanova, Analysis. Audit, 6, 17-27 (2018) https://doi.org/10.26794/2408-9303-2018-5-6-17-27

34. V. L. Tambovtsev, I. A. Rozhdestvenskaya, The Manager, 11(1), 2-14 (2020) https://doi.org/10.29141/2218-5003-2020-11-1-1

35. N. Almazova, D. Bylieva, V. Lobatyuk, A. Rubtsova, In: SPBPU IDE'19: Proceedings of Peter the Great St. Petersburg Polytechnic University International Scientific Conference on Innovations in Digital Economy, 37 (Association for Computing Machinery, New York, 2019) https://doi.org/10.1145/3372177.3373340

36. T. A. Baranova, A. M. Kobicheva, E. Y. Tokareva In ICDTE 2019. The 3rd International Conference on Digital Technology in Education, ACM International Conference Proceeding Series, 77-81. (Association for Computing Machinery, New York, 2019) https://doi.org/10.1145/3369199.3369245

37. V. Glukhov, N. Vasetskaya, In: M. Shestopalov (Ed.), IEEE VI Forum strategic partnership of universities and enterprises of hi-tech branches, Science. Education. Innovations (SPUE), 17-21 (IEEE, St. Petersburg, 2017). https://doi.org/10.1109/ivforum.2017.8245958

38. N. N. Pokrovskaia, M. A. Petrov, M. A. Gridneva, In: S. Shaposhnikov (Ed.), Third international conference on human factors in complex technical systems and environments (ERGO) 28-31 (IEEE, St. Petersburg, 2018) https://doi.org/10.1109/ERGO.2018.8443851

39. A. I. Rudskoy, A. A. Alersandrov, M. P. Chubik, A. I. Borovkov, P. I. Romanov, Primary professional educational programs of higher education. Their planning and implementing in compliance with labour market requirements. Field of education «Engineering and technonlogy» (POLYTECH PRESS, St. Petersburg, 2018) https://doi.org/10.18720/SPBPU/2/id18-113

40. T. V. Semenova, Zh. M. Sizova, T. N. Malahova, A. A. Malygin, M. B. Chelyshkova, S. A. Knyazeva, Medical news of North Caucasus 14, 118-122 (2019)

41. S. I. Gerasimov, S. B. Mogilnitskiy, A. I. Chuchalin, P. S. Shamritskaya, S. O. Shaposhnikov, High. Edu. in Russia 3(199), 5-16 (2016) 
42. A. M. Dolgorukov, V. V. Zyryanov, P. V. Malakhov, L. V. Temnova, High. Edu. in Russia 10, 5-16 (2015)

43. A. L. Drondin, High. Edu. in Russia 29(2), 41-49 (2020) https://doi.org/10.31992/0869-3617-2020-29-2-41-49

44. D. Tyutin, In: V.M. Bychenkov (Ed.), Human resources management and modern personnel requirements: professional standards and employment services, 153-163 (AKF "Politop", 2019)

45. A. G. Tanova, L. I. Evseeva, E. G. Pozdeeva. I. R. Trostinskaya, St. Petersburg State Polytechnic Uni. J. of Engineering Sci. and Technology. Humanities and Soc. Sci. 9(1), 90-101 (2018) http://doi.org/10.18721/JHSS.9110

46. A. Y. Hou, M. Ince, S. Tsai, Asia Pacific Education Review 16, 95-106 (2015) https://doi.org/10.1007/s12564-015-9358-9

47. O. Jerez, C. Orsini, B. Hasbún, Quality assurance syst. High Edu. Policy 31, 121-138 (2018) https://doi.org/10.1057/s41307-017-0046-8

48. A. Kel'sina, Issues of territorial development 1(41), 1-12 (2018) https://doi.org/10.15838/tdi/2018.1.41.5

49. O. A. Matveeva, High. Edu. in Russia 7, 19-28 (2019) https://doi.org/10.31992/08693617-2019-28-7-19-28

50. O. V. Sirotkina, T. N. Ishchuk, E. V. Parmon, E. V. Shlyakhto, Rus. J. of Cardiology, 9, 41-45 (2016) http://dx.doi.org/10.15829/1560-4071-2016-9-41-45

51. T. V. Matveeva, N. V. Mashkova, O. N. Tkacheva, O. G. Safina, Edu. and sci. 1(20), 137-150 (2015)

52. S. V. Laskovets, I. V. Naletova, Socio-economic phenomena and processes 13(1), 6573 (2018) https://doi.org/10.20310/1819-8813-2018-13-1-65-73

53. Regulation on professional public accreditation of educational programs (2019) https://www.dropbox.com/s/7rq1a40n7vh5yfd/\%D0\%9F\%D0\%9E\%D0\%9B\%D0\%9E $\%$ D0\%96\%D0\%95\%D0\%9D\%D0\%98\%D0\%95\%20\%D0\%BE\%20\%D0\%9F\%D0\%9 E\%D0\%90.pdf?dl=0 (Last accessed 12.12.2020)

54. Automated information $\mathrm{w}$ for the monitoring of professional public accreditation of educational programs (2020) https://accredpoa.ru/accreditators/index/view/id/ (Last accessed 12.12.2020)

55. Kaliningrad chamber of Commerce and industry http://kaliningrad.tpprf.ru/ru/services/166963/ (Last accessed 22.12.2020)

56. Association of classical universities of Russia http://www.acur.msu.ru/ru/akredit.php (Last accessed 23.12.2020)

57. Z. S. Byrne, J. W. Weston, K. Cave, Research in Science Education 50, 1417-1433 (2020) https://doi.org/10.1007/s11165-018-9738-3 (Last accessed 23.12.2020)

58. B. P. Lynch, In: M. Miwa, S. Miyahara (eds), Quality assurance in LIS education, 187196 (Springer, Cham, 2015) https://doi.org/10.1007/978-1-4614-6495-2_12

59. K. H. Chan, A. Y. Hou, Asia Pacific Edu. Rev. 17, 1-11 (2016) https://doi.org/10.1007/s12564-016-9415-z

60. S. A. Litvinova, O. M. Belinskaya, State and Municipal Management. Scholarly notes, 2, 35-41 (2018) https://doi.org/10.22394/2079-1690-2018-1-2-35-41

61. V. V. Stroev, T. B. Kulikova, Yu. A. Demasova, Human Sci.: Humanities Res. 3(37), 1551-156 (2019) https://doi.org/10.17238/issn1998-5320.2017.30.151 
62. A. I. Rudskoy, A. I. Borovkov, P. I. Romanov, High. Edu. in Russia 27(1), 151-162 (2018)

63. A. V. Ponachugin, Monitoring of education quality as an essential factor of training bachelor's degree students in applied information science. Vestnik of Minin Uni. 8(1), 4-27 (2020) https://doi.org/10.26795/2307-1281-2020-8-1-4

64. N. V. Rumyantsev, O. A. Bondareva, J. of Moscow Uni. of the Ministry of Internal Affairs of Rus. Fed. 2, 251-256 (2020) https://doi.org/10.24411/2073-0454-2020-10107

65. S. A. Ivanov, Scholarly notes of Transbaikal State Uni. 11(3), 180-188 (2016) https://doi.org/10.21209/2308-877X-2016-11-3-180-188

66. D. C. Dugarova, S. E. Starostina, Scholarly Notes of Transbaikal State Uni. Professional education. 6, 52-60 (2015) 